\title{
Chronic non puerperal uterine inversion secondary to uterine leiomyoma misdiagnosed as advanced cervical cancer: a rare case report
}

\author{
Sunanda N.*, Lokeshchandra HC, Sudha R., Kavya D. Sharma
}

Department of Obstetrics and Gynaecology, Mysore Medical College and Research Institute, Mysuru, Karnataka, India

Received: 04 November 2016

Accepted: 30 November 2016

\section{* Correspondence:}

Dr. Sunanda N.,

E-mail: sunanda_n@ @rediffmail.com

Copyright: (C) the author(s), publisher and licensee Medip Academy. This is an open-access article distributed under the terms of the Creative Commons Attribution Non-Commercial License, which permits unrestricted non-commercial use, distribution, and reproduction in any medium, provided the original work is properly cited.

\begin{abstract}
Uterine inversion is an uncommon complication of parturition which often occurs in the immediate postpartum period. The chronic non puerperal uterine inversion is a rare gynaecological clinical condition which usually results from tumour arising from the fundus of the uterus. Here we are present a case of 45 year old lady with non-puerperal chronic uterine inversion secondary to fundal sub mucous fibroid polyp which was initially misdiagnosed as carcinoma cervix. An attempt at vaginal restoration and removal was difficult. Hysterectomy was done by vaginal approach. Pre and Postoperative course in the hospital was uneventful. Early diagnosis and appropriate surgical treatment of the inverted uterus are important to prevent further complications.
\end{abstract}

Keywords: Chronic uterine inversion, Fibroid polyp, Misdiagnosed, Non-puerperal

\section{INTRODUCTION}

Uterine inversion is a rare clinical condition with only a few cases of chronic non puerperal inversion of the uterus quoted in the literature .On an average a gynaecologist may only see one case in their lifetime. ${ }^{1}$ Uterine inversion is described as part of the uterus indenting towards and eventually prolapsed through the dilated cervix resulting in uterus being turned inside out. It is categorised as puerperal/obstetric and non-puerperal/gynaecological complication. ${ }^{2}$ Non puerperal uterine inversion can be classified into acute, sub-acute and chronic based on the timing of the event. Acute inversion occurs within 24 hours of birth; sub-acute uterine inversion occurs after 24 hours and within 4 weeks, whereas chronic is rare and occurs after 4 weeks. ${ }^{3}$ Chronic non puerperal uterine inversion is often associated with uterine pathology. Prolapsed fibroids tend to be the most common inciting factor with occasional reports of inversion associated with uterine neoplasm and endometrial polyps. The recto abdominal method is often the most diagnostic clinical method, as the vagina is occupied by the inverted uterus and on bimanual examination there is dimpling of the uterine fundus. ${ }^{2}$ Treatment depends on the stage of the inversion and correction is usually by surgical methods. Vaginal hysterectomy for chronic non puerperal inversion poses unique challenges to the surgeon.

\section{CASE REPORT}

A 45 year old peri menopausal tubectomised lady with four term vaginal deliveries in the past was referred from primary health centre for menorrhagia and dysmenorrhoea since three months without any complaints inter menstrual spotting, white discharge per vagina or post coital bleeding. Patient was a known case of diabetes mellitus since seven years on regular treatment. She came with pelvic ultrasonography report done two months back which revealed endometrial hypertrophy with normal uterine size and contour. On 
general examination patient was anaemic without any abnormality in the systemic examination. Pelvic examination revealed a $7 \times 6 \mathrm{~cm}$ fragile mass occupying whole of vagina, cervix could not be seen or felt separately. Uterine size could not be made out. Parametrium was free on per rectal examination. The initial evaluation suggested severe anaemia secondary to advanced cervical carcinoma. Examination under anaesthesia and staging was attempted but this was however inconclusive due to profuse haemorrhage. As the mass was friable and bleeding on touch biopsy of the mass was taken. Histopathological report of the mass showed pleomorphic cells with autolytic changes. After few days patient complained of excessive bleeding per vagina and noticed a mass protruding out of the introitus while straining at stools. On gynaecological examination there was irreducible well circumscribed mass of $10 \times 7$ $\mathrm{cm}$ with sloughing surface protruding through introitus. The uppermost part of the protruding mass was beefy red in appearance, with no active bleeding, the lower part of the mass was necrotic with a demarcation between the two (Figure 1). Cervix was not felt separately. On sound test (passing uterine sound through the cervix) no uterine cavity was demonstrable. Patient did not tolerate examination well. We could not identify the Ostia of the fallopian tubes. Pelvic ultrasonography could not identify the uterus in the pelvis. Ultrasound probe on the mass revealed a central stripe of echogenic tissue suggestive of endometrium. Diagnosis of chronic uterine inversion was made with associated pathology of submucosal fundal fibroid polyp. Correction of anaemia was done with three pints of packed red cell transfusion and the infected mass was treated with glycerine magnesium sulphate dressing and parenteral antibiotics. Patient was posted for vaginal hysterectomy as she was parous and had completed her family. Cervical ring was identified (Figure 2) and was cut posteriorly and access gained to the funnel of inversion. Under the guidance of fingers incision was extended upwards and uterus was bisected after doing polypectomy. Inversion could not be completely reverted back because of the marked hypertrophy and edema of the tissues. Uterovesical fold of peritoneum was opened and bladder was pushed upwards. Ligaments were identified clamped, cut and ligated from inside. Bisected uterus with cervix was removed. Vault was closed by haeney's stitch (Figure 3). Per operative blood loss was approximately 500ml. Post-operative period was uneventful. Patient was discharged on the $10^{\text {th }}$ postoperative day. Histopathological report of the specimen showed red degeneration of fibroid with no evidence of malignancy.

\section{DISCUSSION}

Uterine inversion refers to descent of the uterine fundus to or through the cervix, so that the uterus is turned inside out. Inversion can be acute or chronic. Acute inversion causes severe pain and hemorrhage and almost always an aftermath of delivery whereas chronic inversion is insidious and characterised by pelvic discomfort, vaginal discharge, irregular vaginal bleeding and anemia. ${ }^{4}$ Non Puerperal uterine inversion is very rare indeed in literature there is no figure about incidence of its occurrence. ${ }^{1}$ There are only few case reports of chronic non puerperal uterine inversion. Most reports cite a prolapsed fibroid uterus as cause for inversion corresponding to $78.8-85 \%$ of cases. ${ }^{5}$ Non puerperal uterine inversion is usually precipitated by tumors sited at the fundus of the uterus which exerts traction force to cause the inversion. The major factors that contribute to its occurrence are: tumor attachment site, thickness of the tumor pedicle, tumor size, thin uterine wall and dilatation of cervix. Different studies have reported different causative factors of uterine inversion. ${ }^{6}$ Chronic uterine inversion is such a rare clinical condition and over a period of 10years in this institute only 3 cases have been recorded and all those cases were due to uterine fibroid.

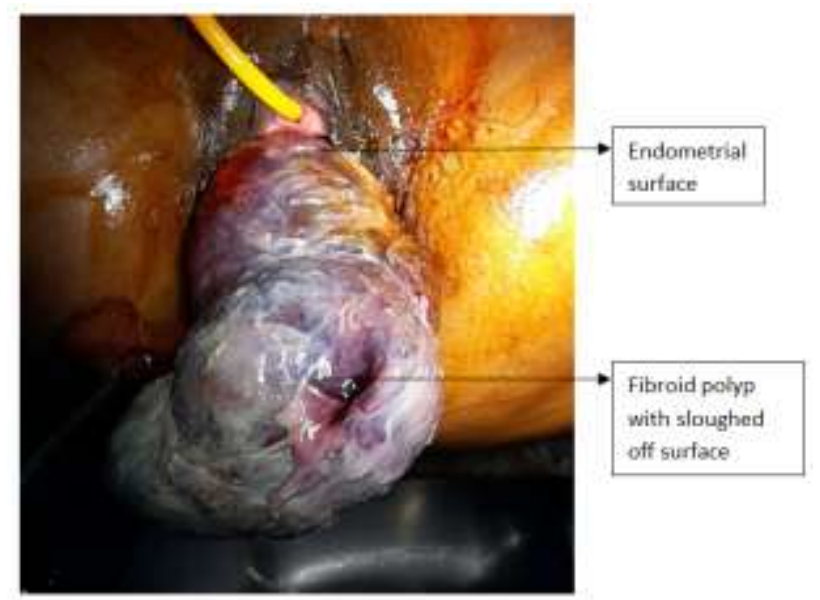

Figure 1: Preoperative (sloughing on the inverted mass).

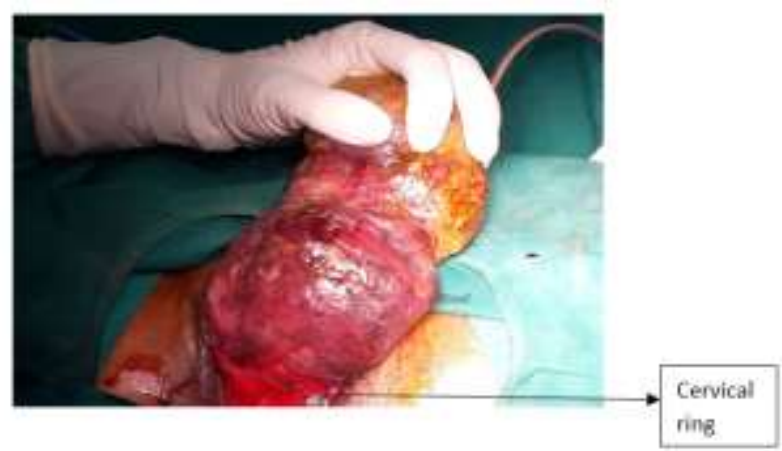

Figure 2: Posterior view showing cervical ring.

The patient we managed had tumour associated chronic inversion in which the implicated tumour was a fundally sited sessile fibroid.

Uterine inversion can be staged as follows: ${ }^{7}$

Stage 1: The uterus is partially turned out

Stage 2: The fundus has passed through the cervix but not outside the vagina. 
Stage 3: The fundus is prolapsed outside the vagina.

Stage 4: The uterus, cervix and vagina are completely turned inside out and are visible.

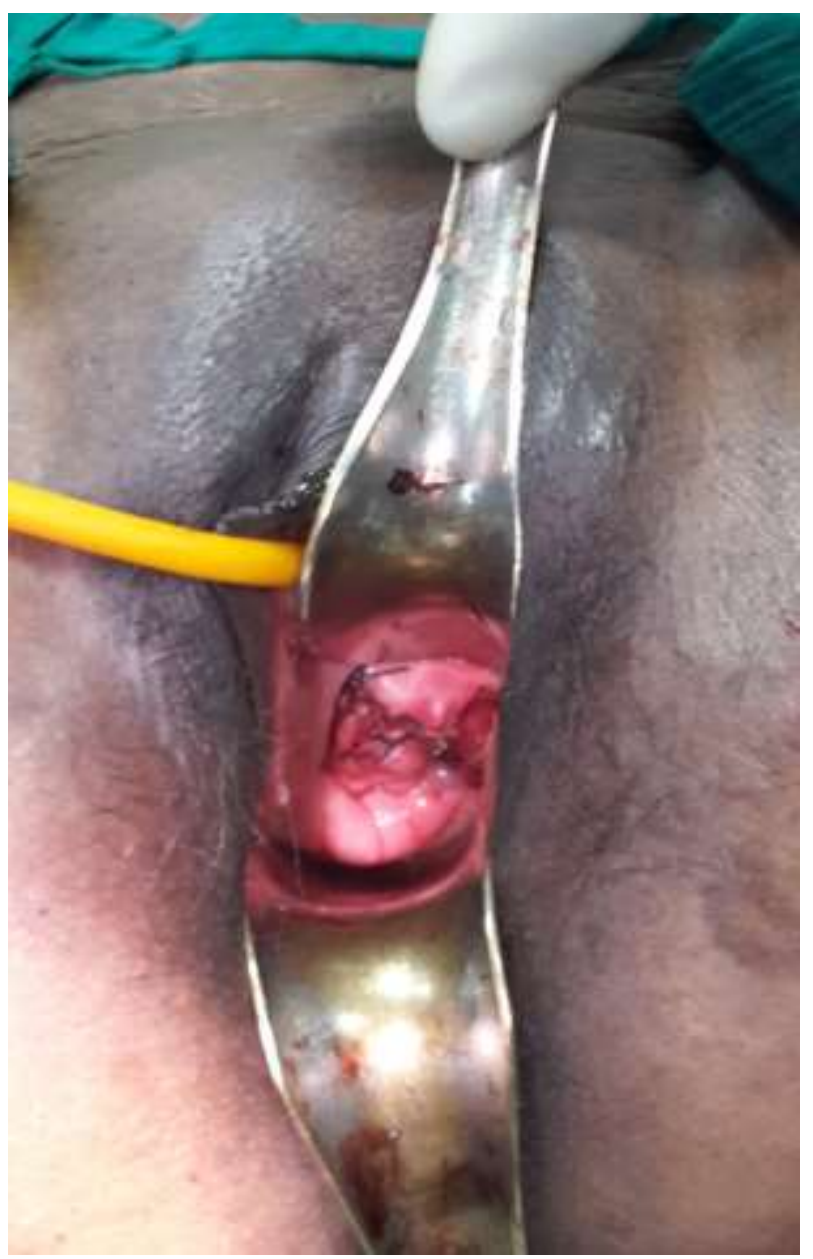

Figure 3: Vault at the end of the surgery.

Due to insidious onset and rare occurrence, the clinical diagnosis of chronic uterine inversion is difficult, especially if inversion is incomplete as seen initially in our case. The diagnosis is based on high index of suspicion. The clinical features may include: lower abdominal tenderness, vaginal bleeding, urinary frequency, dysuria and urgency. Finding a mass coming through the cervix without definite margins of a cervix, absence of the uterine fundus or fundal dimpling during bimanual or rectal examination are strongly suggestive of the diagnosis. The openings of the fallopian tubes may be identifiable if it had been dragged through the endometrial surface. The diagnosis is easier with complete inversion when a bluish red mass is identified from the vulva with a consticting ring of the cervix superiorly. ${ }^{8}$ In other cases, the diagnosis can be difficult.

Imaging procedures such as ultrasound and magnetic resonance imaging will assist the diagnosis. Unfortunately, because of the rare nature of the disorder, uterine inversion frequently goes undetected until surgery unless a high index of suspicion is maintained. Ultrasound examination is the first line imaging investigation. The suggestive features in that include: indentation of the fundal area and depressed longitudinal groove extending from the uterus to centre of inverted uterus. When available magnetic resonance imaging can be useful, the features will include; "U-shaped uterine cavity, thickened and inverted uterine fundus on sagittal section and "bull's eye" configuration on an axial image. Some authors have recommended the use of T2-weighted MRI. ${ }^{8}$ Frozen section of the vaginal mass has been used by some authors for the diagnosis. Demonstration of the endometrium on the surface of the mass will confirm the diagnosis. Biopsy of the mass has definite place if an associated malignancy is suspected as in our case. ${ }^{4}$

Treatment is guided by whether condition is acute or chronic, reproductive wish of patient and cause of the inversion (benign or malignant). Surgery is imperative in chronic inversion unlike in acute inversion where manual repositioning is possible. Many surgical methods (vaginal and/or abdominal) have been described to treat non puerperal uterine inversion. The efficacy of the nonsurgical methods is not clear .Most of the surgical methods described involve reinverting the uterus before proceeding to hysterectomy. Vaginal hysterectomy without reinverting the uterus has been reported. Depending on the clients reproductive desire and associated conditions, surgical reposition or hysterectomy could be done through either abdominal or vaginal conditions. ${ }^{4}$

Huntington abdominal approach involves grasping the round ligaments and the uterus below the area of inversion and slowly pulling up repeatedly until the uterus is re-inverted. The Haultain procedure is where vagino-cervical ring is incised posteriorly and carried up the posterior wall of the uterus until it can be reinverted to its normal anatomy. ${ }^{9}$ Kustner and Spinelli procedures are the commonly used vaginal approaches. Kustner procedure is entering the pouch of douglas vaginally and splitting the posterior aspect of the uterus and the cervix, and reinverting the uterus. In Spinelli operation incision is made on the anterior aspect of the cervix and the uterus is reinverted. ${ }^{9}$ After both the procedures the uterine incision needs to be repaired after repositioning, if the fertility is wished or otherwise can be proceeded for routine vaginal hysterectomy. However in our case reposition of the uterus could not be done completely because of the hypertrophied and edematous tissue and hysterectomy was performed by bisecting the uterus, ligating the ligaments from inside out.

Nevertheless, in places where the facility and expertise exist the repair could be done laparoscopically. Auber et $\mathrm{al}^{10}$ described a case of non-puerperal uterine inversion using combined laparoscopic and vaginal approach. This method of approach is now emerging from available literature. 


\section{CONCLUSION}

Chronic non puerperal uterine inversion is a rare condition that is difficult to manage even for the experienced gynaecologist. Clinical diagnosis is often difficult and can be misdiagnosed as carcinoma cervix. A high index of suspicion is required for the diagnosis of chronic uterine inversion. It can be described as a "gynaecological near miss". Treatment is surgical that includes both abdominal and vaginal approaches. An attempt at vaginal restoration and removal has been reported but is difficult. Uterine inversion has a good outcome if diagnosed and managed timely.

Funding: No funding sources Conflict of interest: None declared

Ethical approval: Not required

\section{REFERENCES}

1. Kagne SS, Thawal YA. An extremely rare case of chronic non puerperal inversion treated by myomectomy preceding vaginal hysterectomy. Journal of Evolution of Medical And Dental Sciences. 2013;2(46):8976-9.

2. Shabbir S, Ghayasuddin M. Chronic non puerperal uterine inversion secondary to sub-mucosal fibroid. J Pak Med Assoc. 2014;64(5):586-8.
3. South Australian perinatal practice guidelines-Uterine inversion. 2014 p. 2-6.

4. Umeononihu OS. Uterine leiomyoma associated non puerperal uterine inversion misdiagnosed as advanced cervical cancer; A case report. International journal of surgery case reports. 2013;4(11):1000-3.

5. Lupovitch A, England ER, Chen R. Non-puerperal uterine inversion in association with uterine sarcoma: case report in a 26-year-old and review of the literature. Gynecol Oncol. 2005;97(3):938-41.

6. Muhammed Z, Ibrahim SA. Chronic Non-puerperal uterine inversion: Case series. Nigerian Journal of Basic and Clinical Sciences. 2012;9(2):87-90.

7. Belfort MA, Dildy III GA. postpartum hemorrhage and other problems of the third stage. In: James DK, Weiner $\mathrm{CP}$, Steer PJ, Gonik B, Crowther C, Robson SC, editors. High risk pregnancy management options. 4th ed., St. Louis: Elsevier Saunders; 2011. p. 1307-1308.

8. Occhionero M, Restaino G, Ciuffreda M, Carbone A, Sallestio G, Ferrandina G. Uterine inversion in association with uterine sarcoma: a case report with MRI findings andr review of literature. Gynecologic and obstetric investigation. 2012;73(3):260-4.

9. Shaw's Textbook of Operative Gynaecology By Marcus E Setchell, C. N. Hudson 7th edition. 2011.

10. Auber M, Darwish B, Lefebure A, Ness J, Roman H. Management of non-puerperal uterine inversion using a combined laparoscopic and vaginal approach. American Journal of Obstetrics and Gynecology (United States). 2011:204(6):7-9.

Cite this article as: Sunanda N, Lokeshchandra HC, Sudha R. Sharma KD. Chronic non puerperal uterine inversion secondary to uterine leiomyoma misdiagnosed as advanced cervical cancer: a rare case report. Int J Reprod Contracept Obstet Gynecol 2017;6:344-7. 